\title{
Transformations in Elementary Teachers' Pedagogical Reasoning: Studying Teacher Learning in an Online Graduate Program in Engineering Education
}

\author{
Dr. Jessica Watkins, Vanderbilt University \\ Jessica Watkins is Assistant Professor of Science Education at Vanderbilt University.
}

\section{Dr. Merredith D. Portsmore, Tufts University}

Dr. Merredith Portsmore is the Director for Tufts Center for Engineering Education and Outreach as well as a Research Assistant Professor at the Center. Merredith received all four of her degrees from Tufts (B.A. English, B.S. Mechanical Engineering, M.A. Education, $\mathrm{PhD}$ in Engineering Education) and has been a member of the Center for Engineering Education and Outreach for 18 years, previously serving as the Director of Outreach and a program manager. Her research interests focus on how children engage in designing and constructing solutions to engineering design problems and evaluating students' design artifacts. Her outreach work focuses on creating resources for K-12 educators to support engineering education in the classroom. She is also the founder of STOMP (stompnetwork.org), LEGOengineering.com (legoengineering.com), and the new Online Teacher Engineering Education Program (teep.tufts.edu).

\section{Dr. Rebecca D. Swanson, Tufts University}

Dr. Swanson is a post-doc scholar with the Center for Engineering Education and Outreach at Tufts University, where she studies teacher learning in an online professional development course on teaching and learning engineering. She earned her doctorate in Curriculum \& Instruction in Science Education from the University of Colorado Boulder, as well as a Bachelor's Degree in Molecular, Cellular, and Developmental Biology from UC Santa Cruz. Prior to graduate school, Dr. Swanson was an elementary STEM educator for a children's science center, teaching STEM courses in both formal and informal learning environments. 


\title{
Transformations in elementary teachers' pedagogical reasoning: Studying teacher learning in an online graduate program in engineering education
}

\author{
Jessica Watkins, Vanderbilt University \\ Merredith Portsmore, Tufts University \\ Rebecca Swanson, Tufts University
}

\section{Introduction}

At the end of an 18-month in-service teacher education program for engineering, Margaret, a veteran elementary teacher, talked about a recent engineering lesson she taught to her third-grade class. The students had been building rockets for a stomp launcher. They planned, built, tested and revised their rockets over multiple class sessions. In an interview, Margaret recounts her interactions with one student during testing:

This kid, Charlie, he was trying so hard to make an air-tight rocket. 'Cause he figured, mine is not going far because it's leaking. That the air is going through it and it's leaking, so it's not going very far. 'So I am going to make an air-tight rocket.' Well, he had layers of wax paper, aluminum foil. He pinched off every little corner he could find. Little holes he covered with metal washers, which then had a lot of masking tape. [laughter] This thing weighs a ton! So I'm sure it doesn't have any air leaks, but it weighs a ton!

...I'm watching him put all these layers on... and I am letting him put all these layers on it... 'Cause if I just tell him, 'Honey, that's going to be too heavy,' he's just gonna, you know, be disappointed and take my word for it. Or he's such a lovely polite person, he's not going to argue with me, and he hasn't tested it yet, so he doesn't have the evidence to counterclaim or whatever. So I would have really stolen from him the opportunity to think that through. (Interview 5)

In her reflection, Margaret recalls specific details of Charlie's latest rocket design. She notes that he had been attending to a particular problem - how to keep the rocket from leaking out air. She also acknowledges her own understanding of the mechanics underlying his design - the weight of the rocket needed to be considered alongside how well it traps air. While she was aware that Charlie's design was too heavy to be launched, she let him try out his ideas on his own. She reasons that if she were to intervene and point to the rocket's weight, she would not be providing him with opportunities to gather his own evidence, analyze his design's performance, and identify the critical mechanisms and trade-offs for himself. She considers how this intervention would affect his engagement in the activity and how it would restrict his agency to discover new ideas for himself.

In this moment, Margaret expresses a stance towards teaching engineering as providing opportunities for students to explore and learn from their design ideas, particularly when those ideas do not perform as expected. She considers the engineering design process (EDP) not just as a series of steps for students to go through in their designing, but as ways for students to reflect on and learn from their design. Notably, this stance is markedly different from how she says she 
taught her students in the past: "Oh I would have totally told him that it was going to be too heavy." (Interview 5)

We open with this example to illustrate the kind of pedagogical sense-making and reflection that, we argue, is critical for teaching engineering design. Teaching engineering involves being flexible in noticing and responding to student thinking [1]-[3], drawing on nuanced understandings of the design process [4]-[7] to make decisions about how to support students' engineering learning. However, to date there are few examples in the literature that look at the development of teachers' pedagogical reasoning for supporting students' engineering learning. These depictions are critical for building deeper understandings of how teachers learn to facilitate students' engineering and for informing engineering teacher education to better foster teachers' learning. We argue that an important step is to explore in-depth how teachers like Margaret develop the productive stances exhibited in the opening quotes.

In this paper, we examine teacher learning in the context of an 18-month online graduate certificate program in engineering education, in which two courses focused on engineering content and two courses on engineering pedagogy. We present a detailed case study of an elementary teacher who exhibited productive shifts in their pedagogical stances toward students' engineering. We detail changes in her sense-making about teaching and learning engineering over four interviews, including as she discussed videos of students' engineering from others' and her own classroom. Our goals are to (1) position the transformations in pedagogical reasoning as novel outcomes for engineering teacher education and (2) provide detailed depictions of the contextual and dynamic nature of these transformations over the course of a program for engineering educators.

\section{Teacher learning in engineering}

To situate our focus on teachers' pedagogical reasoning in engineering design, we briefly review the existing work on teacher learning in engineering education. There has been a wealth of research on teachers' conceptions of engineering or STEM [8]-[10] and how teacher educators can support teachers to better understand what engineers do and how it relates to science [11], [12]. Similarly, researchers have examined teachers' content knowledge in engineering [13]. In particular, professional development has focused on increasing teachers' familiarity with and understanding of the engineering design process [14] and supporting them to select lessons that reflect the design process [15], [16]. Others have pointed to the importance of teachers learning design as a problem-solving process. Rather than the EDP being a set of step-by-step instructions, teachers need to see it as comprising of a set of overlapping practices that can help orient students as they navigate the messy, unpredictable process of designing [17], [18]. Lastly, a strand of work has explored elementary teachers' perspectives on design failures [19], [20] as an integral part of learning engineering.

In addition to drawing on understandings about engineering and the design process, teaching involves actively planning engineering units, launching design tasks, supporting students' group work, and leading whole-class discussions to facilitate students' engineering learning. The field has started to examine these aspects of engineering pedagogy, in terms of practices and moves [3], [21]-[23]. There have been accompanying efforts to characterize pedagogical content knowledge in engineering [6], [24], [25] and how teachers' own disciplinary experiences can influence their goals for teaching [26]. Our prior work has emphasized the 
importance of pedagogical responsiveness, looking at what teachers with varying degrees of experience teaching engineering notice in students' thinking and how they respond [2], [27].

Building on this work, we take the perspective that teaching engineering requires teachers' judgment and reflection. Teaching engineering is complex; the ill-defined and dynamic nature of engineering requires teachers' flexible judgment to support students' work.

Furthermore, there can be pedagogical tensions that emerge between competing disciplinary, socio-emotional, and equity-focused goals, particularly in interdisciplinary units [28]. Just as engineers consider trade-offs in their designing, elementary teachers need to grapple with the trade-offs in their own instruction, motivating a focus on teachers' pedagogical reasoning and reflection in engineering. In particular, we are interested in how teachers make sense of the relationships between discipline of engineering design, pedagogy, and student thinking. We draw on the construct of stance to refer to teachers' verbalized sense-making about these aspects of teaching and learning engineering. In the next section, we describe our theoretical perspective that teachers' stances can be dynamic and contextual, in interaction with local and broader contexts of their work.

\section{Dynamic perspectives of teacher learning}

In our examinations of teachers' reasoning and learning, we draw on scholarship that considers teachers' cognition as dynamic and context-sensitive [29]-[33]. This perspective stands in contrast to models in which teachers progress through stages of development or that presume that teachers' knowledge, views, and beliefs are stable and coherent. Instead, our perspective recognizes that teachers' stances can be dynamic, in interaction with the local and broader contexts.

Illustrating how teachers' stances can be sensitive to context, Tang et al. [34] presented a case describing a teacher's different approaches toward the scientific process during a ninthgrade environmental science class. At the start of class, the teacher was oriented toward introducing the scientific method and how it might be tested on a standardized assessment. She initially focused on the scientific method as a series of ordered steps that do not overlap and key vocabulary that the students would need to know for the test. After this discussion, she prompted her students to design their own experiments for comparing earthworm habitats and started to transition away from a focus on the steps and vocabulary of the scientific method, emphasizing instead on students' brainstorming and sense-making about the phenomena. This example highlights the dynamic nature of this teacher's stance toward the scientific process, at first taking a stance toward the scientific process as a set of linear, ordered steps, but then shifting to focus on science as inquiry.

This and other examples [1], [31], [32] show that teachers can exhibit shifts in their stances in both moment-to-moment interactions and across contexts, such as from professional development to classroom teaching. From this dynamic perspective, teachers' learning or progress has been conceptualized as developing stabilities in their stances [33], [35], in which they express similar reasoning more consistently over time and across contexts.

We apply this dynamic and context-sensitive perspective on teacher learning in engineering, looking at teachers' stances toward teaching and learning design. By not presuming teachers' stances to be consistent, in this case study we examine teacher reasoning for both variability and stability over time. Our objective is to characterize a teacher's stances, identify 
meaningful shifts over the course of the program, and look for evidence of stability in her reasoning. Specifically, we ask:

1) Within an online engineering education program for in-service teachers, what stances does this teacher take toward learning and teaching engineering design?

2) What shifts do we observe in her stances?

3) For these shifts, what evidence do we see of stabilities in her stances, particularly across contexts of engineering?

\section{Study context}

This study takes place in the Tufts Teacher Engineering Education Program (TEEP), an online asynchronous program in engineering education for in-service teachers, STEM specialists, and other educators. Educators take four graduate courses over eighteen months. TEEP was designed to help educators not only learn engineering content, but also develop their pedagogical reasoning and practice to support students' engineering learning. Two courses focus on pedagogy, including what it means to learn engineering and instructional approaches to support this learning (Figure 1). The program has four central goals, in line with recent recommendations for engineering teacher educators and professional development [14], [18]:

GOAL I: $\quad$ Engage teachers in engineering content and process

GOAL II: Support teachers' learning of responsive pedagogy in engineering

GOAL III: Enable teachers to plan, modify \& select curricula with attention to student thinking

GOAL IV: Build a community of educators in engineering nationally and internationally

In Table 1, we summarize the key instructional activities in TEEP, how they align to our four central goals, and in which courses teachers engage in these activities.

\begin{tabular}{clc}
\hline Goals & Key instructional activities & Course \\
\hline \multirow{2}{*}{ I \& IV } & $\begin{array}{l}\text { Learning engineering content (e.g. gear ratios) and reading about \& } \\
\text { discussing accounts of professional engineering }\end{array}$ & 1 \& 3 \\
\cline { 2 - 3 } & $\begin{array}{l}\text { Engaging in engineering design process in authentic challenges } \\
\text { Analyzing student thinking in one-on-one interviews with learners }\end{array}$ & $1 \& 3$ \\
\hline & $\begin{array}{l}\text { Reading data-rich journal articles in engineering education } \\
\text { II, III, \& IV }\end{array}$ & $\begin{array}{l}\text { Discussing videos of students' engineering work, including from own } \\
\text { classroom }\end{array}$ \\
& $\begin{array}{l}\text { Reflecting on pedagogical moves and structures to support students' } \\
\text { engineering }\end{array}$ & $2 \& 4$ \\
\hline
\end{tabular}

Table 1. Goals and instructional activities in the four courses of the program.

\section{Data collection}


To understand how elementary educators shifted in their stances toward teaching engineering, we recruited 11 research participants in the 2017-18 TEEP cohort. Each participant consented to collecting videos of students' engineering from their classroom, participating in research interviews, and allowing researchers to analyze their coursework. For this paper, we examined participants' research interviews and videos from their classroom.

\section{Classroom videos}

At three different points in the program we asked participants to collect video of consented students engaging in engineering in their classroom. For each submitted video, a researcher noted moments that showed evidence of student thinking or teacher-student interactions around engineering. In their subsequent research interview, we then asked participants to watch and discuss what they noticed during a brief clip (2-7 minutes) of their video.

\section{Research interviews}

Participants were interviewed a total of six times over the course of the program using a semistructured protocol, via web-based videoconferencing technology (typically Skype). At the start of the program (Interview 1), each participant was individually interviewed by a member of the research team. Participants were asked about their views and goals toward teaching engineering, their reasons for enrolling in the program, and a description of their most recent engineering unit. In both the initial and final interviews (Interviews 1 and 6) participants watched two videos of students' engineering, collected from our prior projects (we refer to these "research videos" in Figure 1). The research videos were chosen because they showed evidence of students' thinking in engineering, including their planning of a design solution, giving and receiving feedback on a prototype, and analyzing their solution using evidence [36]. After watching each research video, teachers were asked what they saw in the video as relevant to them, as a teacher of engineering, and what they might do next if they were the teacher.

Interviews that took place after each course (Interviews 2-5) began with questions about participants' experiences in the prior course and the significant things they had learned. During Interview 4, teachers watched and discussed another research video, while in Interviews 2, 3, and 5 participants were asked to watch and reflect on their own classroom videos (e.g., videostimulated recall interview [37]). For these videos, teachers were asked what they saw as relevant for themselves as teachers of engineering and what they might do next or change about their pedagogical moves after having seen the video.

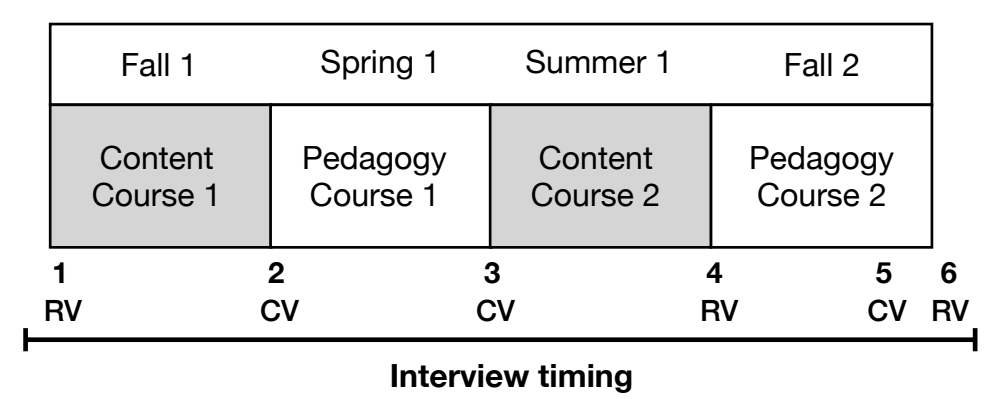


Figure 1. TEEP course sequence over 4 semesters (18 months). Bottom line shows timing of the six teacher interviews and whether teachers viewed research videos (RV) or videos from their classroom $(\mathrm{CV})$.

\section{Analytic methods}

\section{Motivation for a case study approach}

We motivate a case study approach first based on our data. In contrast to studies and reports that generalize elementary teachers' prior experiences and attitudes toward engineering, we found a great deal of diversity among educators. In the program and in our research population, we observed that elementary engineering educators were not monolithic in their backgrounds, institutional contexts, perspectives, or teaching. We expected (and found) that there was much to be learned by not aggregating over this variability across our participants. Instead, we sought to better understand teachers as individual learners and examine the distinct dynamics of their learning. As such, we find that a case study approach is appropriate for such a naturally bounded unit of study [38].

Furthermore, we argue that a case study approach to studying teacher learning is warranted based on the nascent state of the field in engineering education. Rich case studies offer starting points for theory-building, identifying fruitful constructs and patterns that can be investigated further. As others have pointed out [39], [40], this approach is common in the medical field, in which medical case studies serve to identify potential mechanisms and hypotheses in unique instances which can then be studied at different scales, including large- $N$ experiments.

In particular, we position these case studies as showing what is possible for teacher learning; critical cases [40] for educating engineering teachers. As the field works to characterize and support productive pedagogical approaches to teaching engineering, we see the contribution of these case studies in terms of their generativity [41] for thinking of novel targets for teacher learning in engineering, specifically in showing how shifts in teachers' pedagogical reasoning in engineering is a worthy and attainable outcome of engineering teacher education.

\section{Selection and description of case study participants}

After each round of interviews, the research team met to discuss the 11 participants. The interviewer summarized key points from the interview, referencing written notes in a shared data spreadsheet. We then informally compared summaries from previous interviews to get a sense of changes in how participants talked about engineering, how they approached teaching engineering, and what they noticed in classroom videos. Through this process, we identified several teachers on whom to focus our analysis, ultimately selecting a single case to share in this paper.

Alma is a veteran $3^{\text {rd }}-5^{\text {th }}$ grade science teacher in a rural, racially-diverse public school in the southeastern region of the US. She had done numerous STEM units with her students but wanted to learn more about engineering. We identified her initially because we noted after her second interview how she was talking very differently about the engineering design process as 
compared to her first interview. We selected her as a case to characterize the possible shifts in her stances and examine variabilities and stabilities.

\section{Analyzing interviews}

For this paper, we focused data analysis on the first four interviews with Alma. One researcher watched each interview and developed a content log of the discussion in five-minute intervals. We then met as a team to discuss the content logs. We used a constant comparative approach [42] to identify emergent themes of teachers' learning, look for evidence in other interviews, and refine our categories. We then turned to the transcript to highlight passages that reflected these themes, looking for both confirming and disconfirming evidence. After this sampling, we systematically coded the interview transcripts, identifying her stances towards: (1) students' capabilities for doing engineering, (2) students' communicative practices in engineering, (3) student ideas in STEM, (4) teaching and learning EDP, and (5) the role of idea exploration in engineering. Using these sampled and coded excerpts, we developed analytic memos for each interview, highlighting where we saw variability and stability in her stances and comparing across interviews to describe shifts in teacher's reasoning. It was at this stage that we refined our themes, narrowing our focus to Alma's stances toward the EDP. We then developed narrative analyses, independently revisiting interview transcripts and classroom video to confirm our claims.

\section{Researcher positionalities}

We note that two of the researchers (second and third authors) were instructors for Alma; the other researcher (first author) was not affiliated with TEEP while Alma was enrolled in the program. Our research team therefore brought both insider and outsider perspectives on this participant. The second and third authors contributed deeper insights into Alma and provided access "to 'insider' meanings" in her interviews (Horn \& Little, 2010, p. 187). The first author brought an external perspective on this participant, supporting the team to remain grounded in the data. This coupling of insider and outsider perspectives supported us to consider multiple interpretations of data, hold each other accountable, and resolve discrepancies, which, in turn, served to bolster our claims.

\section{Case analysis of Alma's stances toward the EDP}

We now present the case of Alma, arguing that she exhibited dramatic shifts in her stances toward teaching and learning the engineering design process (EDP). At the start of the program, she was stable in treating the EDP as a series of linear steps that students and engineers progress through. After engaging and reflecting on her own engineering in the first course, she started to express a more fluid stance when talking more abstractly about the EDP but continued to take it up as a linear process in her classroom teaching. By the end of the program, Alma exhibited a growing stability across contexts in her stance toward the EDP as a fluid set of overlapping practices that students and engineers could engage in.

\section{Alma's initial stances}

Alma's stance toward the nature of the EDP was consistent throughout her first interview. She was familiar with the steps of a particular EDP, treating them as discrete steps that students needed to know and do. This stance stands in contrast to depictions of professional practice, in 
which these steps represent different overlapping practices that designers navigate when solving problems. When describing STEM units in her classroom, Alma emphasized the prominence of the EDP and its associated vocabulary:

... [my students are often] engineering something using the engineering design process. It's hanging right up over here above my bulletin board... I refer to that all the time. I teach my kids the engineering vocabulary. It's listed right there on the poster board. My kids know what a challenge is, they can define it too. Tell you what it means. Collaboration, constraints, criteria, innovation, product, and prototype. So I'm teaching them that... (Interview 1)

In her description of her engineering instruction, she highlighted the steps of the EDP on a poster hanging in her room, stating that she referenced it "all the time" with her students. While this quote did not give evidence of how she used the EDP in her classroom, her emphasis on vocabulary reflected a stance toward engineering knowledge as being about defined terms learning engineering is learning the particular steps and vocabulary.

She also talked about her instruction in terms of the steps of the EDP. She structured her lessons so that students would engage in each step of the design process sequentially. She referred to the steps as requirements; students "had to" plan, create, and improve. She also talked about how she organized her class to make time for these steps, and she struggled to make time for "improve." While her familiarity with the steps of the design process is important for supporting students' engineering, we argue that her stance toward the EDP does not reflect professional engineering practice, in which the EDP represents the kinds of activities that engineers fluidly move between to solve a problem.

In her discussions of the research videos of students' engineering during Interview 1, she also made sense of students' work solely based on what step of the EDP they were supposed to be doing. After watching the first research video, before the interviewer even finished her first question, Alma asked about the EDP:

Well I got a question first. In that video. That appears to be, to me, the communication part. Am I correct on that? If you're looking at the engineering design process: ask, imagine, plan, create, improve, communicate. Is that the communication step, that they were just doing? (Interview 1)

During the introduction of the second research video, later in Interview 1, she again interrupted the researcher to ask about the step of the design process: "So this is the communication part again? Right?" To make sense of a video of classroom engineering, Alma had to first identify which step students were on. Her question presumed that these steps were discrete and came after the other steps (ask, imagine, plan, create, improve, then communicate). Notably, we saw the students in the videos engaging in multiple kinds of design activities, beyond communicating their design. The class imagined how their device would work in the setting, tested its functionality, brainstormed new design ideas, and made rapid improvements to their design. Alma did not notice any of these productive aspects of students' activities. Instead, she talked about how, if she were the teacher, she would ask students to go back through the steps of the design process again, since she felt that they were not yet ready to communicate their design. 
They should write down the problem, plan and draw a picture, and, importantly, agree on a design before they can build or communicate it with others.

In sum, in her first interview, Alma expressed a stable stance toward the engineering design process as consisting of discrete steps that need to be taught to and scaffolded for students. With this stance, her interpretations of student thinking in the videos were limited to the particular step of the EDP she thought they were on, leading her to miss productive aspects of students' engineering.

\section{Shifting in her stances toward the EDP}

After the first course, in Interview 2, Alma expressed remarkable shifts in her stances toward the EDP. She directly connected the changes in her thinking to her own experiences engaging in engineering design during Content Course 1 of TEEP:

Well one of the things that I found out in this course and it was really hard for me to kind of break free from it, was that those steps, they don't always go in that order. They go a little bit everywhere. Because I was doing that [final project and it was like, ok, I had to ask myself, how am I going to build this thing? I was just kind of imagining things in my mind, what it would look like. ... But I did find as I was creating, that I was going back and I was kind of like, wait a minute, this won't work this way, so I'm going to have to go back now to the ask part...And then I was going back to the asking and imagining again and then I was planning it out again, adding to my drawing that I'd done. ...Then I got feedback back from my colleagues and then I was going back to [the] asking phase. [I]t was all over the place. It was nothing like that [pointing at the EDP representation in her classroom]... [The EDP] goes all over the place. It doesn't have to go in that order... [B] ut I find myself telling my kids, now it doesn't have to go in that order. It can bounce and go all over the place. (Interview 2)

Alma talked about the EDP as being more fluid and unpredictable than she previously thought. She grounded this with an example of her own experience jumping between the different practices of the design process. For instance, while she was creating her final project for the first content course, she found that she had to go back to ask more questions about a part of her design that was not working. She incorporated research throughout the design process, rather than containing it to a particular phase, prior to imagining or creating her solution. She reflected on how her new perspective on the design process shaped how she introduced it to her students. She still found the representation posted in her classroom helpful for her teaching, but she no longer frames it as a linear process, instead talking about how a designer can "bounce" around to the different parts and the process can "go all over the place."

While the above quote provides evidence that Alma changed how she talked about the design process with her students, there is also evidence that she continued to think about the steps as a linear scaffold with her students' engineering. In the same interview, as she shared the context around a video of her recent engineering unit in her classroom, she introduced the students' engineering in terms of the linear steps that they had already completed. She also used the EDP to justify what she did next as a teacher: 
Researcher: And when you-- so after this stuff that was happening in the video, the next thing you all did, I hear you say, is testing. Like how did you decide that that was the next thing to do?...

Alma: $\quad$ It was just the way that I just sat down and decided to plan out the lesson. OK we're going to we're going to build it. We're going to create it, build it, then we're going to test it. Then we're going to improve it, then we'll test it again.

Researcher: Is that part of the engineering process? Like, was that informed by that? Alma: Yes it was.

(Interview 2)

In this quote, Alma talked about planning out each of the students' activities in terms of a linear depiction of the EDP. When engaging in her own engineering, she was responsive to decide what she would do next based on what was productive for her designing. However, in her teaching she directed students to engage in the next step of the EDP, without considering whether that was the productive activity based on students' work.

Furthermore, there is also evidence that shifting around the steps of the EDP would be problematic for her. When she talked about how the students were taping their wheels to the axle, she suggested that she could have looked at their designs before they started building and established as a constraint that they could not tape their wheels. She evaluated that as a teaching move based on how it would affect their progression through the EDP: "But that would've caused us to go back, to have to go back and re-plan if I had done it that way." (Interview 2) Alma's quote is consistent with a stance that the EDP is a linear set of steps to help her students progress through; going back to the planning step would be a problem. In her stance toward the EDP in her own engineering, going back to plan was a productive part of her designing; this contrast highlights the context sensitivity in her stance.

\section{Developing stability in her stances toward the EDP with students' engineering}

In the previous section we argued that there were significant shifts in how Alma talked about the EDP between the first and second interviews; she started recognizing it as more dynamic and fluid. However, these shifts seemed limited to her reflections of her own engineering and how she introduced the EDP to her students. When her students were engaged in engineering design, she seemed to maintain her initial stance toward the EDP as comprised of sequential steps. In the third interview, after the second course (Pedagogy Course 1), there is evidence that she started to take an even more fluid and open stance toward the process with her students' engineering. In the following quote, she talked about how she structured lessons around a new technology, Ozobots, that her school had acquired:

[A colleague] wanted to find a lesson on [website] that we could do with [Ozobots]. And I'm like, no, we don't need to start there with the training. We actually need to let [the students] kind of play around with the code sheet that's on there and see what the Ozobot does with each one of those codes and then have them actually design and create their own track that the OzoBot can follow using those codes. So I've already trained 11 classrooms in my school, and I have stressed, this is tinkering. That's what you're doing. You were finding out how this works. Um, and even some of the teachers that have trained has said, I like that word tinkering. It is better than saying we're going to play. 
They have learned so much just by tinkering, so that was another journal entry [44] that's kinda changed my thinking a little bit about myself because I see that I guess I don't allow enough time for in my classroom and uh, I see the importance of it, you know, because even though it might look like play to some, to somebody else in my school, is actually they are learning and they are figuring out how something works. That's what engineering is, you know, it's learning how something works. (Interview 3)

In this quote, Alma reflected how she has supported changes towards a new instructional approach in her school. Instead of setting up a structured lesson plan, Alma advocated for letting students play around with the Ozobots and code sheet. This approach reflected a more open and fluid perspective on her students' engineering by allowing them unstructured time to figure out the technology rather than going through a set of directed steps. Instead of talking about engineering in terms of steps and terminology, as she did in her first interview, Alma now describes engineering as "learning how something works." While her definition is too general to capture the nature of engineering, it represents an important shift in her thinking away from narrower conceptions of engineering (i.e., her emphasis on vocabulary) to a more open one, which she used to allow her students to engage in a wider range of activities to support their learning.

We also see here how she is making connections with her new perspective on learning engineering with the norms and expectations of school. In particular, the word "tinkering" offers her a way to make the students' exploration in the design process be more consistent with what their administration and colleagues expect of classroom activity. Labeling students' work as play, on the other hand, she saw as in tension with those expectations. By making connections to her particular institutional setting, we argue that she was developing stability in her shifting stances toward students' engineering.

There was also evidence of Alma's growing stability in what she attended to in students' engineering. In the fourth interview, Alma watched another research video, which showed students working together to plan their design. When reflecting on what the students were doing, Alma noted the fluidity and overlapping nature of students' design work:

You know, they're, they're going through a lot of steps of the engineering design process already right there in the video. ...Well, I mean they're asking questions, definitely. They're imagining, they're planning out, they're drawing. They've made a creation with the pencil going on top of the bottle. They're talking through and trying to improve how both ideas could work. They are communicating. They're doing everything right there in that video. It's kinda scary. [laughter] (Interview 4)

Alma volunteered that she sees "everything" in the design process in what the students are doing in the video. In contrast to the first interview, in which she classified students' work solely in terms of which step of the EDP students were supposed to be on, here she noticed the different ways in which the students' activities reflect multiple steps of the EDP. Her noticing in this video and how she structured the unit on Ozobots both suggest that her stance toward the EDP was becoming stable across contexts: it is not just in her own designing or in abstracted conversations about the design process that she sees it as fluid and overlapping activities, but now also in students' work. 


\section{Discussion}

Prior research has studied elementary teacher learning in engineering primarily through the lens of teachers' perceptions of engineering and content knowledge [11], [15]. This focus makes sense, given both the novelty of engineering in K-6 education and teachers' lack of prior experience in engineering. This work informed the design of TEEP; teachers took two courses on engineering content, engaging in authentic design tasks themselves to develop new understandings of the discipline. This paper extends the focus on teachers' engineering knowledge to examine how teachers apply this knowledge in their teaching, that is, how they make sense of these disciplinary understandings in planning design tasks, noticing student thinking, and making instructional decisions.

We presented a case study showing one teacher's transformations in her pedagogical reasoning in engineering in an online graduate program. We focused on aspects of her reasoning that were disciplinary-specific: Alma expressed new ways of reasoning about teaching and learning the engineering design process. We purposefully selected this case given the exemplary changes in her reasoning; we are not arguing that she is representative of all the teachers in TEEP. Instead, we position this case as revelatory, as providing generative ways of thinking about teacher learning in engineering. We argue that the shifts in Alma's stances should inform central goals for teacher education in engineering.

This case also highlights the context-sensitivity of teachers' reasoning. Alma expressed a dramatic shift in talking about the engineering design process as being fluid and dynamic after her first engineering content course, but there was evidence that this stance was not a meaningful part of her teaching until later in the program. This analysis provides further evidence that what teachers express in one setting may not be consistent with what they say or do in other settings. This finding motivates researchers' sensitivity in assessing teachers' disciplinary understandings; what teachers express on surveys or when talking about engineering in an abstract sense may not reflect the understandings they draw on when teaching [45], [46].

The dynamic and context-sensitive nature of teachers' reasoning also suggests limitations to our claims of stability in this case study. Given the online nature of the program, we were limited in our access to teachers' classroom instruction; while teachers collected video from their classroom, these provided only occasional windows into their pedagogical stances with their students. To bolster our claims, we triangulated data from Alma's classroom videos, reflections in research interviews, and program coursework to look for consistency as evidence of her stability in their stances.

Future directions of our research involve building on this analysis to explore ways in which teachers develop stability in their stances. In particular, we are looking at how teachers' pedagogical reasoning in engineering is entangled with their interactions within institutional settings, cultural norms, and personal lives. For one, we observed Alma developing artifacts, such as lesson plans, that supported their stances toward the EDP. She wrote and taught an engineering lesson with a more dynamic perspective toward the design process as part of an application for a teaching award. We conjecture that the teachers' reorganization of their lessons and other school artifacts stabilizes their stances in these contexts. We also saw Alma's engagement in deliberate sense-making across contexts as contributing to their stability. Alma used the term "tinkering" as a way to bridge her values for students' idea exploration to the institutional norms and expectations of her school. Lastly, we are exploring how teachers' personal relationship to the discipline contributed to their pedagogical reasoning; Alma shared a 
personal narrative about how her new understandings of engineering shaped their retrospective understandings of her family history. We see these additional lenses as contributing new perspectives on teacher learning, bringing together issues of pedagogy, epistemology, and identity that have thus far been treated separately in the literature.

\section{Conclusion}

As elementary educators begin to incorporate engineering into their classroom, there are both challenges and opportunities for engineering teacher educators to effect change in the elementary classroom [17], [18]. This paper argues for increased attention to the role that teachers' pedagogical reasoning plays in achieving authentic forms of engineering in classrooms. We show that productive shifts in teachers' pedagogical reasoning in engineering are attainable, documenting a detailed case within an extended online program that focuses both on content and pedagogy. This case motivates future research that examines both what contributes to these shifts and how to design engineering teacher education programs to support teachers' transformations.

\section{Acknowledgements}

We are grateful to TEEP teachers, particularly Alma, for sharing their thinking and classroom teaching with us. We also acknowledge their students, who were willing to be videotaped to support their teachers' learning. We thank Andrew Elby and Kristen Wendell for their feedback on earlier drafts of this work. This material is based upon work supported by the National Science Foundation under Grant Number 1720334.

\section{References}

[1] A. D. Robertson, R. E. Scherr, and D. Hammer, Responsive Teaching in Science and Mathematics. New York, NY: Routledge, 2015.

[2] J. Watkins, M. E. McCormick, E. Milto, M. Portsmore, K. Spencer, K. B. Wendell, and D. Hammer, "Data-based conjectures for supporting responsive teaching in engineering design with elementary teachers," Sci. Educ., pp. 1-23, 2018.

[3] B. M. Capobianco, J. Delisi, and J. Radloff, "Characterizing elementary teachers' enactment of high-leverage practices through engineering design-based science instruction," Sci. Educ., vol. 102, no. 2, pp. 342-376, 2018.

[4] K. Dorst and N. Cross, "Creativity in the design process: co-evolution of problemsolution,” Des. Stud., vol. 22, no. 5, pp. 425-437, Sep. 2001.

[5] N. Cross, Designerly Ways of Knowing. London: Springer-Verlag, 2007.

[6] D. Crismond and R. S. Adams, "A Scholarship of Integration : The Matrix of Informed Design,” J. Eng. Educ., vol. 101, no. 4, pp. 738-797, 2012.

[7] S. R. Daly, R. S. Adams, and G. M. Bodner, "What Does it Mean to Design? A Qualitative Investigation of Design Professionals' Experiences," J. Eng. Educ., vol. 101, no. 2, pp. 187-219, 2012.

[8] H. Wang, T. J. Moore, G. H. Roehrig, and M. S. Park, "STEM Integration : Teacher Perceptions and Practice STEM Integration : Teacher Perceptions and Practice," J. Pre- 
College Eng. Educ. Res., vol. 1, no. 2, pp. 1-14, 2011.

[9] M.-C. Hsu, S. Purzer, and M. E. Cardella, "Elementary Teachers' Views about Teaching Design, Engineering, and Technology," J. Pre-College Eng. Educ. Res., vol. 1, no. 2, 2011.

[10] C. P. Lachapelle, C. Cunningham, and A. Lindgren-Streicher, "Elementary Teachers' Understandings of Engineering and Technology," in American Society of Engineering Education Annual Conference Proceedings, 2006.

[11] J. Radloff and S. S. Guzey, "Investigating Changes in Preservice Teachers' Conceptions of STEM Education Following Video Analysis and Reflection," Sch. Sci. Math., vol. 117, no. 3-4, pp. 158-167, 2017.

[12] J. Radloff and S. Guzey, "Investigating Preservice STEM Teacher Conceptions of STEM Education," J. Sci. Educ. Technol., vol. 25, no. 5, pp. 759-774, 2016.

[13] M. M. Hynes, "Middle-school teachers' understanding and teaching of the engineering design process: a look at subject matter and pedagogical content knowledge," Int. J.

Technol. Des. Educ., vol. 22, pp. 345-360, 2012.

[14] J. E. Reimers, C. L. Farmer, and S. S. Klein-Gardner, "Standards for preparation and professional development for teachers of engineering," J. Pre-College Eng. Educ. Res., vol. 5, no. 1, pp. 40-60, 2014.

[15] S. S. Guzey, K. M. Tank, H. Wang, G. H. Roehrig, and T. J. Moore, “A High-Quality Professional Development for Teachers of Grades 3-6 for Implementing Engineering into Classrooms," Sch. Sci. Math., vol. 114, no. 3, pp. 139-149, 2014.

[16] S. S. Guzey, T. J. Moore, and M. Harwell, "Building Up STEM: An Analysis of TeacherDeveloped Engineering Design-Based STEM Integration Curricular Materials," J. PreCollege Eng. Educ. Res., vol. 6, no. 1, pp. 10-29, 2016.

[17] C. Cunningham, "Elementary teacher professional development in engineering: Lessons learned from Engineering is Elementary," Washington, DC, 2008.

[18] C. Cunningham and W. S. Carlsen, "Teaching Engineering Practices," J. Sci. Teacher Educ., vol. 25, no. 2, pp. 197-210, 2014.

[19] P. S. Lottero-Perdue and E. A. Parry, "Perspectives on Failure in the Classroom by Elementary Teachers New to Teaching Engineering," J. Pre-College Eng. Educ. Res., vol. 7, no. 1, pp. 47-67, 2017.

[20] P. S. Lottero-Perdue and E. A. Parry, "Elementary Teachers' Reflections on Design Failures and Use of Fail Words after Teaching Engineering for Two Years," J. PreCollege Eng. Educ. Res., vol. 7, no. 1, pp. 1-24, 2017.

[21] M. L. Aranda, R. Lie, S. S. Guzey, M. Makarsu, A. Johnston, and T. J. Moore, "Examining Teacher Talk in an Engineering Design-Based Science Curricular Unit," Res. Sci. Educ., pp. 1-19, 2018.

[22] C. Cunningham and G. J. Kelly, "Framing Engineering Practices in Elementary School Classrooms," Int. J. Educ. Res., vol. 33, no. 1, pp. 295-307, 2017.

[23] S. S. Guzey and E. A. Ring-Whalen, "Negotiating science and engineering : an exploratory case study of a reform-minded science teacher," Int. J. Sci. Educ., vol. 40, no. 7, pp. 723-742, 2018.

[24] R. S. Adams, T. Forin, M. Chua, and D. Radcliffe, "Characterizing the work of coaching during design reviews," Des. Stud., vol. 45, pp. 30-67, 2016.

[25] R. S. Adams, M. Chua, and D. Radcliffe, "Making Design Pedagogical Content Knowledge Visible within Design Reviews," in Design Thinking Research Symposium 
Proceedings, 2014, pp. 1-47.

[26] K. B. Wendell, J. Swenson, and T. S. Dalvi, "Epistemological framing and novice elementary teachers' approaches to learning and teaching engineering design," J. Res. Sci. Teach., 2019.

[27] A. W. Johnson, K. B. Wendell, and J. Watkins, "Examining Experienced Teachers' Noticing of and Responses to Students' Engineering," J. Pre-College Eng. Educ. Res., vol. 7, no. 1, pp. 1-11, 2017.

[28] K. B. Wendell, J. Watkins, and A. W. Johnson, "Noticing, assessing, and responding to students' engineering: Exploring a responsive teaching approach to engineering design," in Proceedings of the 123rd American Society for Engineering Education Annual Conference and Exposition, 2016.

[29] R. S. Russ and M. J. Luna, "Inferring teacher epistemological framing from local patterns in teacher noticing," J. Res. Sci. Teach., vol. 50, no. 3, pp. 284-314, 2013.

[30] D. M. Levin, D. Hammer, and J. E. Coffey, "Novice Teachers' Attention to Student Thinking," J. Teach. Educ., vol. 60, no. 2, pp. 142-154, 2009.

[31] T. M. Philip, “An 'Ideology in Pieces' Approach to Studying Change in Teachers' Sensemaking About Race, Racism, and Racial Justice," Cogn. Instr., vol. 29, no. 3, pp. 297-329, 2011.

[32] J. Richards, "Exploring what stabilizes teachers' attention and responsiveness to the substance of students' scientific thinking in the classroom," University of Maryland, College Park, 2013.

[33] J. Watkins, J. E. Coffey, A. C. Maskiewicz, and D. Hammer, "An account of progress in teachers' epistemological framing of science inquiry," in Teachers' Personal Epistemologies: Evolving Models for Transforming Practice, G. Schraw, J. Brownlee, L. Olafson, and M. Vandervelt, Eds. Information Age Publishing, 2017.

[34] X. Tang, J. E. Coffey, A. Elby, and D. M. Levin, "The scientific method and scientific inquiry: Tensions in teaching and learning," Sci. Educ., vol. 94, no. 1, pp. 29-47, 2010.

[35] D. Hammer, A. Elby, R. E. Scherr, and E. F. Redish, "Resources, framing, and transfer," in Transfer of Learning: Research and Perspectives, J. Mestre, Ed. Greenwich, CT: Information Age Publishing, 2005.

[36] K. B. Wendell, C. Wright, and P. Paugh, "Engineering design as reflective decisionmaking: How elementary school students make collaborative planning and redesign choices during formal engineering learning experiences," J. Eng. Educ., vol. 106, no. 3, pp. 356-397, 2017.

[37] J. Lyle, "Stimulated recall: a report on its use in naturalistic research," Br. Educ. Res. J., vol. 29, no. 6, pp. 861-878, 2003.

[38] S. B. Merriam, Qualitative Research and Case Study Applications in Education. San Francisco, CA: Jossey-Bass, 1998.

[39] B. A. Danielak, A. Gupta, and A. Elby, "Marginalized Identities of Sense-Makers: Reframing Engineering Student Retention," J. Eng. Educ., vol. 103, no. 1, pp. 8-44, 2014.

[40] R. K. Yin, Case study research: Design and methods. Washington, DC: Sage Publications, 2017.

[41] D. Hammer, J. Gouvea, and J. Watkins, "Idiosyncratic cases and hopes for general validity: What education research might learn from ecology," Infanc. y Aprendiz., vol. 41, no. 4, pp. 625-673, 2018.

[42] B. G. Glaser and A. L. Strauss, The discovery of grounded theory: Strategies for 
qualitative research. Aldine de Gruyter, 1967.

[43] I. S. Horn and J. W. Little, "Attending to Problems of Practice: Routines and Resources for Professional Learning in Teachers' Workplace Interactions," Am. Educ. Res. J., vol. 47, no. 1, pp. 181-217, 2010.

[44] G. M. Quan and A. Gupta, "Tensions in the Productivity in Design Task Tinkering," in American Society of Engineering Education Annual Conference Proceedings, 2015, pp. $1-12$.

[45] I. Y. Salter and L. J. Atkins, "What Students Say Versus What They Do Regarding Scientific Inquiry," Sci. Educ., vol. 98, no. 1, pp. 1-35, 2013.

[46] G. Rowe and A. M. Phillips, "A comparison of students' written explanations and CLASS responses," in Physics Education Research Conference Proceedings, 2016, pp. 280-283. 